\title{
Frontières
}

\section{Quelques réflexions de... Luc Blanchet}

\section{Luc Blanchet}

Volume 12, numéro 1, automne 1999

Suicides, générations et culture

URI : https://id.erudit.org/iderudit/1075919ar

DOI : https://doi.org/10.7202/1075919ar

Aller au sommaire du numéro

Éditeur(s)

Université du Québec à Montréal

ISSN

1180-3479 (imprimé)

1916-0976 (numérique)

Découvrir la revue

Citer ce document

Blanchet, L. (1999). Quelques réflexions de... Luc Blanchet. Frontières, 12(1),

86-86. https://doi.org/10.7202/1075919ar d'utilisation que vous pouvez consulter en ligne.

https://apropos.erudit.org/fr/usagers/politique-dutilisation/ 


\section{Quelques réflexions de... Luc Blanchet \\ médecin, président du Comité de la santé mentale du Québec}

La communauté médicale - la psychiatrie en particulier - met l'accent sur la méconnaissance et la sousestimation des troubles mentaux, notamment le trouble dépressif majeur, pour expliquer l'augmentation des suicides au Québec. Si cet élément peut jouer un rôle, il ne doit cependant pas occulter les facteurs sociaux liés au phénomène. Comment, en effet, ne pas prendre en considération les changements sociaux incroyablement rapides survenus au Québec au cours des quarante dernières années? Pratique religieuse, transformation de la famille, précarité de l'emploi, augmentation de l'écart entre riches et pauvres, pour ne nommer que ceux-là. Sans omettre le culte contemporain de la performance, qui atteint toutes les sphères de la vie, spécialement l'école et le travail, avec les attentes et la pression sociale correspondantes qui s'exercent sur les individus, indépendamment ou presque de leurs vulnérabilités.

Certes, les ruptures amoureuses, les difficultés liées aux études et au travail, bref, les occasions d'échec de l'idéal du moi, n'ont jamais manqué. Mais au-delà de ces «facteurs précipitants», il y a aussi la souffrance inhérente à la condition humaine, et particulièrement celle, souvent extrême, des personnes les plus vulnérables de notre société. Comment l'interpréter, cette souffrance, quel sens lui donner, comment la vivre, en l'absence de références claires et d'espoirs apaisants aux plans social et spirituel? Aussi, si l'on peut dégager une notion centrale pour traduire un phénomène par ailleurs multifactoriel, je dirais que c'est la «perte du sens de la vie» dans le contexte historique, social, politique et spirituel du Québec d'aujourd'hui, qui pourrait le mieux rendre compte de l'augmentation du nombre des suicides. 